\title{
O ASSÉDIO MORAL E A IDENTIDADE DAS TRABALHADORAS
}

\author{
THE HARASSMENT AND THE \\ IDENTITY OF FEMALE WORKERS
}

Lara Parreira de Faria Borges lara.parreirafb@gmail.com

Ricardo Macedo de Britto Pereira rjmacedo@superig.com.br

Recebido em: 8-3-2014

Aprovado em: 23-11-2015

Sumário: Introdução. 1. Definições de assédio moral. 2. Assédio Moral: gestão pela incitação e flexibilização das relaçóes de trabalho. 3. As pretensôes de reconhecimento e a afirmação da dignidade dos trabalhadores. 4. Assédio moral e discriminação de gênero. 5. A dificuldade em se comunicar experiências.6. O papel da justiça do trabalho na preservação da identidade das trabalhadoras. Conclusão. Referências.

\section{Resumo:}

O assédio moral é uma prática de violência tão antiga quanto o próprio trabalho. Entretanto, o seu reconhecimento como um problema ou uma disfunção a ser tratada somente ganhou a atenção dos estudiosos ao final do século XX. O atual contexto neoliberal surge com um modo de gestão pela incitação, o qual se vale de práticas de assédio moral para garantir a conformidade dos trabalhadores a um modelo de identidade empresarial que busca eficiência e lucratividade à custa da eliminação de toda dissidência. Nesse sistema forjado no sofrimento psicológico para extrair das vítimas a maior rentabilidade possível, verifica-se que o índice de assédio moral é mais frequente entre mulheres. $\mathrm{O}$ assédio moral, em si, já é uma forma de desqualificar a igual consideração e respeito para com a sua vítima. Quanto se verifica que essa prática de violência é mais recorrente contra

\section{Abstract:}

Workplace Bullying is a practice of violence as old as work itself. However, its recognition as a problem or a disorder to be treated, only gained the attention of scholars by the end of the twentieth century. The current neoliberal context comes up as a way of managing the incitement which depends on the bullying practice to ensure compliance of workers to a model of corporate identity that seeks efficiency and profitability by eliminating all dissent.In this system based on psychological suffering in order to obtain maximum profits from its victims, it appears that the rate of bullying is more frequent among women. Bullying itself is already a way to disqualify equal consideration and respect for their victim. As it appears that the practice of violence occurs more frequently against women, it is noticeable that oppression takes the shape of double discrimination. For a democratic 
mulheres, observa-se que a opressão ganha contornos de dupla discriminação. Para um Estado Democrático de Direito, a igual consideração e respeito pela vida de todos os indivíduos representam o norte de atuação de todos os setores governamentais de forma a preservar identidades, coibir toda forma de discriminação, inclusive discriminaçôes cumuladas.

\section{Palavras-Chave:}

Assédio moral, gênero, igualdade, reconhecimento, emancipação. state of law, equal consideration and respect for the lives of all individuals represents the source of action of all government sectors to preserve identities, curbing all forms of discrimination, including cumulative discrimination.

\section{Keywords:}

Moral harassment, gender, equality, recognition, enfranchisement

\section{Introdução}

O presente artigo busca definir o conceito de assédio moral como prática de violência reiterada, que visa à normalização de condutas, mediante a destruição de identidades individuais e coletivas, com uma tendência maior para a combinação com a discriminação de gênero.

Assim, inicialmente, apresentam-se conceituaçóes de assédio moral. Em seguida, oferece-se um panorama a respeito do contexto neoliberal de flexibilização das relaçóes de trabalho em que se insere o assédio, como forma de gestão pela incitação. Nesse tópico, analisa-se como a ameaça de demissão é combinada com um psicoterror que desequilibra as relações de igual consideração e respeito entre os indivíduos de uma organização empresarial, fragilizando o sentimento de empatia entre as testemunhas e as vítimas de assédio moral, quebrando coletivos e destruindo identidades, em um movimento normalizador que aniquila diferenças.

O tópico sucessivo dá destaque ao reconhecimento da dignidade humana, valor fundante do estado democrático de direito, expressamente previsto em nossa Constituição, mas que frequentemente é afrontado em razão das graves lesóes resultantes de práticas de assédio moral, que, além dos danos às vítimas, contaminam o ambiente de trabalho como um todo.

Adiante, segue uma reflexão a respeito da combinação de um mercado desenraizado com a discriminação de gênero como fomentadores do assédio moral no ambiente de trabalho. Em contraposição a um mercado de trabalho desregulamentado e sem mecanismos estatais de proteção ao trabalhador, propóem-se maneiras de emancipação que permitam uma igualdade de participação e consideração entre os gêneros, como meio de coibir formas de opressão. 
Por fim, reflete-se sobre a dificuldade das vítimas em comunicarem o sofrimento experimentado em um ambiente em que o coletivo encontra-se fragilizado e aponta-se a importância da Justiça do Trabalho como instrumento institucional para dar vazão ao discurso silenciado, em um movimento de concretização de direitos.

\section{Definições de assédio moral}

Conforme Marie-France Hirigoyen afirma, "embora o assédio no trabalho seja uma coisa táo antiga quanto o próprio trabalho, somente no começo desta década [1990] foi realmente identificado como fenômeno destruidor do ambiente de trabalho, não só diminuindo a produtividade como também favorecendo o absenteísmo, devido aos desgastes psicológicos que provoca” (HIRIGOYEN, 2008, p. 65).

Para identificar as práticas de assédio moral nas organizaçôes de trabalho, é necessário delimitar e definir seu conceito de modo a permitir que tal prática de gestão possa ser reconhecida e, posteriormente, combatida.

O assédio moral é definido pela psiquiatra francesa Marie-France Hirigoyen como "qualquer conduta abusiva (gesto, palavra, comportamento, atitude...) que atente, por sua repetição ou sistematização, contra a dignidade ou integridade psíquica ou física de uma pessoa, ameaçando seu emprego ou degradando o clima de trabalho" (HIRIGOYEN, 2002, p. 17).

Outro precursor de estudos sobre o assunto foi o professor Heinz Leymann, pesquisador alemão residido na Suécia, ao trabalhar com casos de "mobbing" - o assédio moral no ambiente de trabalho (HIRIGOYEN, 2008, p. 65), definindo-o da seguinte forma:

Terror psicológico ou mobbing no ambiente de trabalho envolve comunicação hostil e antiética que é direcionada de forma sistemática contra um ou mais indivíduos, principalmente contra um indivíduo, que, em razão do mobbing, é empurrado para uma posiçáo indefensa e desamparada e mantido nesta situação pela perpetuação do mobbing. Essas açôes ocorrem em uma base bastante frequente (definição estatística: ao menos uma vez por semana) e durante um longo período de tempo (definição estatística: ao menos seis meses de duração). Em razão da alta frequência e longa duração do comportamento hostil, o mau trato resulta em considerável miséria mental, psicossomática e social.

Assim, a definição não foca muito nas atividades em si, mas sobre a pesada tensão mental. A origem do foco nas situaçôes psicológicas no local de trabalho é encontrada nas pesquisas médicas sobre estresse: $\mathrm{O}$ pesquisador tenta revelar quando um estressor no local de trabalho pode prejudicar o indivíduo, fazendo com que ele ou ela entre em 
licença médica. A pesquisa empírica sobre assédio moral no local de trabalho revelou estressores psicossociais que causam impacto extremo na saúde da vítima, como pode ser observado através do estudo das seqüências de curso-de-mobbing.

- A definição exclui conflitos temporários e foca-se no ponto de ruptura no qual a situação psicológica começa a desencadear condições patológicas de ordem psiquiátrica e psicossomática. (LEYMANN) ${ }^{1}$ (Tradução livre)

Nesse mesmo sentido, Marie-France Hirigoyen desenvolve a seguinte explicação sobre assédio moral:

Qualquer que seja a definição adotada, o assédio moral é uma violência sub-reptícia, não assinalável, mas que, no entanto, é muito destrutiva. Cada ataque tomado de forma isolada não é verdadeiramente grave; o efeito cumulativo dos microtraumatismos frequentes e repetidos é que constitui agressão. Este fenômeno, no início, pode ser comparado com o sentimento de insegurança existente nos bairros, resumido no termo "incivilidade". Com a continuaçâo sistemática, todas as pessoas visadas se sentem profundamente atingidas.

(...)

O estilo específico de agressão é variável de acordo com os meios socioculturais e setores profissionais. Nos setores de produção, a violência é mais direta, verbal ou física. Quanto mais se sobe na hierarquia e na escala sociocultural, mais as agressōes são sofisticadas, perversas e difíceis de caracterizar. (HIRIGOYEN, 2012, p. 17 e 18)

Assim, meros dissabores eventuais ou conflitos pontuais no ambiente de trabalho não são suficientes para caracterizar o assédio moral. Para tanto, é preciso que haja condutas sistemáticas e repetitivas direcionadas contra uma pessoa ou grupo, de forma a fragilizar a vítima em um período mais prolongado. Esses comportamentos hostis para com a vítima produzem nesta um sentimento de miséria social, além de patologias psicológicas e até físicas.

\footnotetext{
Original: "Psychological terror or mobbing in working life involves hostile and unethical communication which is directed in a systematic manner by one or more individuals, mainly toward one individual, who, due to mobbing, is pushed into a helpless and defenseless position and held there by means of continuing mobbing activities. These actions occur on a very frequent basis (statistical definition: at least once a week) and over a long period of time (statistical definition: at least six months' duration). Because of the high frequency and long duration of hostile behavior, this maltreatment results in considerable mental, psychosomatic and social misery. Thus, the definition does not focus too much on the activities themselves, but rather on the heavy mental strain. The origin of this focus on psychological situations in the workplace is found in medical stress research: The researcher attempts to reveal, when a workplace stressor is likely to injure the individual, causing him or her to go on sick leave. The empirical research on mobbing in the workplace has revealed psychosocial stressors that cause extreme impact on the health of the victim, as can be observed by studying the course-of-mobbing sequences. The definition excludes temporary conflicts and focuses on the breaking point where the psychosocial situation begins to result in psychiatrically or psychosomatically pathological conditions."LEYMANN, Heiz. The mobbingencyclopaedia. Disponivel em: <http://www.leymann.se/English/frame.html> Acesso em: 01/11/2012.
} 
Os estudos mencionados foram pioneiros ao detectarem essas práticas que afetam trabalhador ou grupo de trabalhadores, de forma agressiva, ainda que dissimulada ou sutil em algumas situaçóes, provocando graves lesôes na vida dessas pessoas. O comprometimento da autoestima intensifica o sentimento de não pertencimento ao grupo e a sensação de insegurança, a partir do isolamento das vítimas. Os esforços para a reconstrução individual da capacidade de reação são sistematicamente destruídos, de modo que os danos provocados por essas atitudes tornam-se, em geral, irreversíveis.

Porém, práticas de assédio moral podem ocorrer independentemente da motivação de provocar lesóes ou isolamento em relação a vítimas específicas, dirigindo-se ao grupo de trabalhadores como um todo, como técnica que supostamente interfere nos resultados empresariais, mediante o incremento da produção de bens e serviços.

\section{Assédio Moral: gestão pela incitação e flexibilização das relações de trabalho}

Apesar de as pesquisas demonstrarem os inúmeros danos psicológicos e até físicos, a prática do assédio moral nos ambientes de trabalho é corriqueira, como forma de estimular a produtividade e competitividade entre os empregados inclusive, considerada uma técnica de gestão para motivar o engajamento subjetivo dos trabalhadores nas metas da empresa (ARAÚJO, 2012, p. 69). Nesse sentido, o assédio moral surge como uma forma de "gestão pela incitação", por meio de uma estratégia para extrair maior produtividade dos trabalhadores (SILVA, 2005, p. 15). Na busca pela normalização de condutas, eliminando o diferente, o assédio moral passa a funcionar como sanção normalizadora (ARAÚJO, 2012, pp. 78-79).

O sistema neoliberal, envolvido pela globalização, exige a redução de direitos trabalhistas e inclusive de direitos fundamentais constitucionalmente assegurados, com o fim de obter crescimento econômico e o lucro sem fronteiras (geográficas, morais e jurídicas).

ZygmuntBauman, citando o professor Ricardo Petrella, explica que o fenômeno da globalização se baseia na produção do efêmero, do volátil e do precário, encontrando-se nesse último as relações de emprego flexíveis. (BAUMAN, 1998, p. 86)

As grandes corporaçóes e empresas visualizam o mercado de trabalho com regras excessivamente rígidas e, por isso, demandam uma flexibilização para que os investidores tenham a sensação de dominar a mão-de-obra.(BAUMAN, 1998, p. 112)Assim, transformam o trabalho no oposto do que esse se propóe na medida em que "a ideia de 'flexibilidade' esconde sua natureza de relação social, o fato de que demanda a redistribuição de poder e implica uma intenção de expropriar o poder de resistência daqueles cuja 'rigidez' está a ponto de ser superada" (BAUMAN, 1998, p. 112). 
Em todo o contexto de globalização e busca por eficiência dentro das empresas em que o trabalho torna-se mercadoria e a personalidade do trabalhador não é considerada, o assédio moral é utilizado como meio de gestão para obter mais lucro, segundo acreditam as organizaçôes que o implementam ou toleram sua prática (SILVA, 2005, p. 15). A violência psicológica torna-se um meio flexível que permite, hipoteticamente, a aceleração da produtividade, à medida que a pressão por resultados impulsiona os trabalhadores a serem mais eficientes, sob pena de serem demitidos.

Christophe Dejours define o cenário mundial dos dias atuais como uma "guerra econômica", na qual os menos aptos são excluídos quando não correspondem aos desempenhos sempre superiores de produtividade que são exigidos para que as empresas superem seus concorrentes (DEJOURS, 2007, p. 13).

A perda do emprego e a dificuldade em conseguir uma nova posição no mercado de trabalho promovem o sofrimento por atingirem os alicerces da identidade (DEJOURS, 2007, p. 19). A ameaça dessa exclusão engendra um sentimento de medo e desconfiança entre as pessoas, minando a rede de solidariedade (DEJOURS, 2007, p. 19).

Segundo Pierre Bourdieu, esse discurso gera um sistema que procura destruir os coletivos, buscando tratar apenas com indivíduos, impedindo todo coletivo que possa resistir à lógica do mercado.

Assim se instaura o reino absoluto da flexibilidade, com os recrutamentos por intermédio de contratos de duração determinada ou as interinidades e os "planos sociais" de treinamento, e a instauraçáo, no próprio seio da empresa da concorrência entre filiais autônomas, entre equipes, obrigadas à polivalência, e, enfim, entre indivíduos, através da individualização da relação salarial: fixação de objetivos individuais; prática de entrevistas individuais de avaliação; altas individualizadas dos salários ou atribuição de promoçóes em função da competência e do mérito individuais; carreiras individualizadas; estratégias de "responsabilização" tendendo a garantir a auto-exploração de certos quadros que, sendo simples assalariados sob forte dependência hierárquica, são ao mesmo tempo considerados responsáveis por suas vendas, seus produtos, sua sucursal, sua loja, etc. (...) eis algumas técnicas de submissáo racional que, ao exigir o sobreinvestimento no trabalho, e não apenas nos postos de responsabilidade, e o trabalho de urgência, concorrem para enfraquecer ou abolir as referências e as solidariedades coletivas. (BOURDIEU, 1998, p. 139)

(...) encontram as molas de adesão na insegurança em relação à tarefa e à empresa, no sofrimento e no estresse, não poderia certamente ter sucesso completo, caso não contasse com a cumplicidade de trabalhadores a braços com condiçóes precárias de vida produzidas pela insegurança bem como pela existência - em todos os níveis da 
hierarquia, e até nos mais elevados, sobretudo entre os executivos - de um exército de reserva de mão-de-obra docilizada pela precarização e pela ameaça permanente do desemprego. (BOURDIEU, 1998, p. 140)

Assim, Pierre Bourdieu argumenta que a base dessa ordem econômica, mascarada pelo discurso da "liberdade dos indivíduos", encontra-se na "violência estrutural do desemprego, da precariedade e do medo inspirado pela ameaça de demissão". Para o sociólogo francês, o desemprego "isola, atomiza, individualiza, desmobiliza e rompe com a solidariedade" (BOURDIEU, 1998, p. 140). Assim, até mesmo colegas de trabalho se omitem na defesa das vítimas de assédio moral por medo de também sofrerem represálias, como a demissão.

Christophe Dejours faz a seguinte análise a respeito do surgimento do medo de demissão:

Todos esses trabalhadores vivem constantemente sob ameaça de demissão. O essencial das variaçôes do ritmo de produção (em função do total de pedidos) é absorvido por empregos precários, contratos com prazo determinado e sobretudo contratos emprego-solidariedade (CES).

Em outras palavras, a precariedade não atinge somente os trabalhadores precários. Ela tem grandes consequências para a vivência e a conduta dos que trabalham. Afinal, seus empregos que se precarizam pelo recurso possível aos empregos precários para substituí-los, bem como às demissóes pelo mínimo deslize(...). (DEJOURS, 2006, pp. 50-51)

Nessas circunstâncias, o assédio moral surge como uma forma de "gestáo pela incitação" (SILVA, 2005, p. 15). A procuradora do Ministério Público do Trabalho Adriane Reis de Araújo explica que o assédio moral:

(...) serve à empresa como um instrumento de gestão de seu pessoal, instrumento de normalizaçáo da conduta dos trabalhadores, para o engajamento e controle de todo o pessoal com o fim de manter ou incrementar o ritmo de qualidade da produçáo, sem permitir qualquer reinvindicação em relação às condiçôes de trabalho ou a direitos trabalhistas e silenciando sobre condutas ilícitas ou socialmente reprovadas, de forma a manter incólume a imagem da empresa. (ARAÚJO, 2012, p. 78)

O medo de demissão faz com que as vítimas do assédio moral se calem sobre o sofrimento que passam. A conduta abusiva é implementada como medida de motivaçáo para que os trabalhadores cumpram suas metas, segundo a defesa das empresas (ARAÚJO, 2012, p. 69). 
As empresas e as chefias, ao implementarem a gestão por incitação, não consideram suas consequências. Segundo informa Marie-FranceHirigoyen, essa forma de abuso de poder como estilo de gerenciamento é ineficaz e de pouco rendimento, uma vez que sobrecarrega os funcionários com estresse, que pode levar a erros profissionais e à necessidade de licenças para tratamento de saúde. Como a própria psiquiatra afirma, "uma mão-de-obra feliz é muito mais produtiva. No entanto, um pequeno chefe ou até mesmo a direção mantêm a ilusão de que assim obtêm um máximo de rentabilidade" (HIRIGOYEN, 2008, p. 82).

A vítima do assédio não necessariamente se limita a um único indivíduo (preferencialmente mais frágil que o agressor), mas, nas grandes empresas, "esse abuso pode transmitir-se em cascata, da mais alta chefia ao menor chefe na escala" (HIRIGOYEN, 2008, pp. 82-83).

Além do abuso de poder, há também a figura das manobras perversas. Diferentemente do abuso de poder (que busca vítimas mais fragilizadas), as manobras perversas criam fragilidades na vítima para impossibilitá-la de se defender; assim, o perverso almeja alcançar o poder, mascarando sua própria incompetência, independentemente de preocupaçóes sobre o mal que esteja instituindo para alcançar seus fins (HIRIGOYEN, 2008, p. 86). Nesses termos, Marie-France Hirigoyen relaciona a atuação do perverso com o que Christophe Dejours denomina de "banalização social do mal", ou seja, a necessidade do perverso em alcançar os objetivos impostos por uma autoridade faz com que ele se torne um agente atroz em processo de destruição (HIRIGOYEN, 2008, p. 86).

Para agravar a situação, a pessoa visada para ser o alvo das condutas hostis acaba obedecendo por medo, mas também por um conformismo dos colegas que "não querem ver o que se passa em torno deles" (HIRIGOYEN, 2008, p. 87). Marie-France Hirigoyen explica a razão dessa ausência de empatia:

É o que se dá no atual reinado do individualismo, do "cada um por si". Quem está em torno teme, caso se mostre solidário, ser estigmatizado e ver-se jogado na próxima onda de demissôes. Em uma empresa, não se pode levantar ondas. É preciso vestir a camisa da firma e não se mostrar demasiado diferente (HIRIGOYEN, 2008, p. 87).

Nessas atuações de manobra perversa, Marie-France Hirigoyen relata que o interesse não é apenas no poder que subjugar o outro trará, mas também em "um enorme prazer em usar o outro como objeto, como uma marionete" (HIRIGOYEN, 2008, p. 90). A vítima passa a ser vista como um objeto, sua identidade é negada e não lhe é reconhecido qualquer direito a sentimentos e emoçóes (HIRIGOYEN, 2008, p. 90).

O medo como forma de gestão é utilizado como motor do sistema para paralisar e quebrar o moral do coletivo, porém, para adquirir efetividade, o medo deve ser combinado com formas de recompensa e reconhecimento pelo trabalho prestado, mesmo que por meio de um discurso distorcido de falsas recompensas (DEJOURS, 2007, pp. 58-59). Por 
meio de uma estratégia de distorção comunicacional, os empregados contribuem para a distorção sem se sentirem responsáveis por ela, partindo dos níveis superiores em direção aos subordinados e permeando todo o sistema (DEJOURS, 2007, p. 59). As organizaçôes empresariais individualizaram o relacionamento de seus empregados com o trabalho e suas pressóes como forma de evitar ou, até mesmo, minar contestaçóes e resistências; mas também coletivizaram essa forma de gestão na medida em que aplicam o mesmo padrão de cobrança a todos os empregados de forma massiva para alcançar os resultados de produção.

\section{As pretensões de reconhecimento e a afirmação da dignidade dos trabalhadores}

Nesse contexto, a grande questão que se coloca consiste em que o trabalhador, ao contratar sua força de trabalho, coloca à disposição do empregador seu tempo e força de trabalho, mas não abdica de sua dignidade, autoestima, direito à personalidade, nem mesmo de sua condição de igual como ser humano em relação ao seu empregador ou chefe (ARAÚJO, 2012, p. 77). Como afirma Ricardo José Macêdo de Brito Pereira, "o contrato de trabalho não legitima a supressão de direitos fundamentais, de modo que o trabalhador não perde sua condição de cidadão ao passar pela porta da empresa” (PEREIRA, 2013, p. 142).

$\mathrm{O}$ assédio moral consiste em uma violação da honra, da dignidade, da integridade física e psicológica, da personalidade do trabalhador na medida em que consiste em uma discriminação, que nas palavras de Guilherme Machado Dray é uma "vertente negativa do princípio da igualdade" (DRAY, 1999, p. 114).

O assédio moral destrói a identidade da vítima a ponto de torná-la refém da pressão do assediador que condiciona sua performance no trabalho. Muitas empresas podem argumentar que o assédio moral, como gestâo empresarial, é uma forma de criação do perfil dos empregados e principalmente faz parte da identidade da própria empresa (ARAÚJO, 2012, p. 78). O assédio moral, ao passo em que vitimiza aquele que sofre, acaba por gerar a estima daqueles que não sofrem essa prática ou mesmo daqueles que praticam o abuso.

Axel Honneth propóe como critérios para o reconhecimento a necessidade de uma pessoa ter suas particularidades respeitadas "a fim de desenvolver autoestima, o que (junto com autoconfiança e o autorrespeito) é um ingrediente essencial para uma identidade não distorcida”, por meio de um viés subjetivo por parte de quem reconhece o outro (HONNETH. Apud. FRASER, 2007, p. 124).

Por sua vez, Nancy Fraser avança ao salientar a importância de se conferir um caráter deontológico ao reconhecimento, que possa ser inclusive desvinculado de uma concepção de vida boa ou de uma ética particular, para impedir o reconhecimento de práticas discriminatórias e de segregação, em lugar de contribuir para a inclusão social (FRASER, 2007, p. 124). A filósofa feminista, para evitar a vinculação do reconhecimento a uma 
ética que possa destruir outros indivíduos, pauta-se pela participação dos atores, como membros efetivos de uma sociedade, a fim de romperdeterminados vínculos de dominação e subordinação nas sociedades.

Além do amparo dessas sofisticadas formulações teóricas, nosso ordenamento jurídico possui disposiçôes normativas contra categorias de opressão que levam tanto a um rebaixamento ou degradação moral que comprometem a autorrealização, quanto à subordinação que inviabiliza a efetiva participação da coletividade desfavorecida para alterar estruturas de poder.

Portanto, a cultura corporativa discriminatória, baseada na prática de assédio moral, como forma de gestão empresarial ou por qualquer outra motivação, jamais pode prevalecer em detrimento dos direitos e da proteção da dignidade humana das vítimas, expressamente prevista na Constituição como fundamento da República Federativa do Brasil.

Tais direitos, como advertiu Ronald Dworkin, estão a salvo das deliberaçôes políticas, visando a maximizar resultados. Segundo ele, "às vezes, quando não frequentemente, a maioria tomará decisões injustas sobre os direitos individuais" (DWORKIN, 2007, p. 215). Assim, o constitucionalismo é o instrumento institucionalizado que permite restriçóes ao poder democrático para impedir que a maioria destrua as minorias e, em um conflito entre justiça e equidade, a integridade prevaleça (DWORKIN, 2007, p. 215).

Importante salientar que decisões políticas não existem e se desenvolvem apenas em instituições estatais, mas estão presentes nas relações privadas como as relações de emprego, a gestão empresarial, a organização do mercado. No mercado de trabalho, as chefias munidas de técnicas de gestão pela incitação atuam como verdadeiras maiorias, em virtude de seu elevado poder econômico e diretivo sobre os trabalhadores, os quais, mesmo podendo ser maioria numericamente, em condiçóes de poderio, autonomia e reconhecimento figuram como verdadeiras minorias.

Ao tratar da integridade, Ronald Dworkin faz a seguinte análise sobre a vida em comunidade:

(...) os membros devem pressupor que as práticas do grupo mostram não apenas interesse, mas um igual interesse por todos os membros. Nesse sentido, as associaçôes fraternais são conceitualmente igualitárias. Podem ser estruturadas, e inclusive hierárquicas, da mesma maneira que se verifica em uma família, mas a estrutura e a hierarquia devem refletir o pressuposto do grupo de que seus papéis e suas regras digam respeito aos interesses de todos, e que a vida de uma pessoa não é mais importante que a de nenhuma outra. Se essa condição for observada, os próprios exércitos podem ser organizaçôes fraternais. Não são fraternais, porém, nem geram responsabilidades comunitárias, os sistemas de castas para os quais alguns membros são intrinsecamente menos dignos que outros. (DWORKIN, 2007, p. 243) 
Observa-se que a dignidade da pessoa humana é construída em um processo dialético de interação das pessoas nos ambientes públicos e privados. O ambiente de trabalho é um desses espaços formadores de identidade e dignidade do ser humano.

Jürgen Habermas entende que a dignidade humana é uma construção elaborada por meio do reconhecimento recíproco em um relacionamento igualitário entre os indivíduos, e não uma mera qualidade intrínseca e pré-existente a todo ser humano como algo dado:

Conforme pretendo demonstrar, a "dignidade humana", entendida em sentido moral e jurídico, encontra-se ligada a essa simetria das relações. Ela não é uma propriedade que se pode "possuir" por natureza, como a inteligência ou os olhos azuis. Ela marca, antes, aquela "intangibilidade" que só pode ter um significado nas relaçôes interpessoais de reconhecimento recíproco e no relacionamento igualitário entre as pessoas.

(...)

Com efeito, a subjetividade, que é o que faz do corpo humano um recipiente animado da alma, se constitui a partir das relaçóes intersubjetivas para com os outros. O si mesmo individual surge apenas com o auxílio social da exteriorização e também só pode se estabilizar na rede de relações intactas de reconhecimento.

Depender dos outros é uma circunstância que esclarece a vulnerabilidade do indivíduo em relação aos outros. A pessoa fica exposta de forma completamente desprotegida a feridas em relaçôes das quais ela geralmente depende para o desdobramento de sua identidade e para a defesa de sua integridade - por exemplo, nas relaçôes íntimas de dedicação a um parceiro. Em sua versão descentralizada, a "vontade livre" de Kant não cai mais do céu como uma característica de seres inteligíveis. A autonomia é, antes, uma conquista precária de existências finitas, que só conseguem "se fortalecer" quando conscientes de sua vulnerabilidade física e de sua dependência social. Se este for o "fundamento" da moral, então seus "limites" se explicam a partir dele. É o universo das relaçôes e interaçôes interpessoais possíveis, que necessita e é capaz de impor regras morais. Apenas nessa rede de relaçôes de reconhecimento legitimamente reguladas é que as pessoas podem desenvolver e manter uma identidade pessoal, juntamente com sua integridade física. (HABERMAS, 2010, pp. 47-48)

Jürgen Habermas explica que a socialização faz com que o ser humano individualize sua história após seu nascimento, tornando-se uma pessoa por meio de uma interação intersubjetiva em um contexto público de uma comunidade linguística (HABERMAS, 2010, p. 49).

Assim, ao institucionalizar a prática do assédio moral nos ambientes de trabalho, as empresas e seus diretores acabam por impedir a construção de uma identidade que confira dignidade aos seus trabalhadores. 
Marie-France Hirigoyen afirma que o "psicoterror" no ambiente de trabalho só ganha força e se mantém quando a empresa o ignora ou mesmo o encoraja (HIRIGOYEN, 2008, p. 93). Nesse sentido, a psiquiatra faz a seguinte análise:

Há diretores que sabem tomar medidas autoritárias quando um funcionário não é competente, ou quando seu rendimento é insuficiente, mas não sabem repreender um empregado desrespeitoso ou inconveniente em relação a um(a) colega. "Respeitam" o domínio privado, não se metem nele, alegando para resolver tudo sozinhos, mas não respeitam o próprio indivíduo.

Se a empresa é assim condescendente, a perversão gera a emulação entre indivíduos que não são propriamente perversos, mas que perdem seus referenciais e se deixam persuadir. Não acham mais chocante que um indivíduo seja tratado de maneira injuriosa. Náo se sabe onde está o limite entre o fato de criticar ou censurar seguidamente alguém para estimulá-lo e o fato de persegui-lo. A fronteira corresponde ao respeito pelo outro, mas, em um contexto de competição, todos os direitos - e até o sentido primeiro deste termo, inscrito na Declaração dos Direitos do Homem - são esquecidos.

A ameaça de perder o emprego permite erigir a arrogância e o cinismo como métodos de gerenciamento. Em um sistema de concorrência desenfreada, a frieza e a dureza tornam-se a norma. A competição, sejam quais forem os meios utilizados, é considerada válida e os perdedores são deixados de lado. Os indivíduos que temem o confronto não usam procedimentos diretos para obter o poder. Eles manipulam o outro de maneira sub-reptícia ou sádica a fim de obter sua submissão. Realçam sua própria imagem desqualificando o outro (HIRIGOYEN, 2008, pp. 93-94) (Grifos acrescidos).

Quando a empresa justifica os meios pelos fins que pretende alcançar, ela pode acabar tornando-se um sistema perverso (HIRIGOYEN, 2008, p. 98). No nível de organização da empresa, o processo perverso serve de instrumento para o desenvolvimento da empresa, como meio para obter o melhor rendimento (HIRIGOYEN, 2008, p. 98).

As empresas são complacentes em relação aos abusos de certos indivíduos desde que isso possa gerar lucro e não dar motivo a um excesso de revolta. Em vez de permitir que as pessoas progridam, essas empresas muitas vezes não fazem mais que quebrá-las (HIRIGOYEN, 2008, p. 101).

Marie-France Hirigoyen demonstra que a prática do assédio moral pode ser resultado de uma má organização empresarial ou de um conflito entre pessoas, entretanto, em ambos os casos, se o assédio permanece é porque a empresa assim o admite (HIRIGOYEN, 2008, 
p. 102). Sempre será possível a intervenção da empresa para coibir e buscar soluçóes para o assédio moral, sob pena de prejuízos inclusive econômicos para o empreendimento, uma vez que essa forma de violência é capaz de diminuir a qualidade do trabalho e aumentar seus custos (HIRIGOYEN, 2008, p. 102).

Verifica-se, assim, que o assédio moral, mais que uma forma de gestão adotada atualmente, também encontra reverberações em personalidades narcisistas de chefias que buscam subjugar seus subordinados, de forma a distorcer a identidade e o reconhecimento dos empregados, bem como do olhar dos outros sobre a história da vítima.

Em uma palestra intitulada "O perigo de uma história única” (Original:“Thedangerof a single story"), a novelista ChimamandaAdichie afirma que uma história única se forma quando se repete e se conta uma história várias vezes (ADIECHIE, 2009). Ela explica que em muitos casos quem decide a forma como essa história será contada são aqueles que detêm poder (ADIECHIE, 2009). Assim, aquele que está em uma posição de poder é capaz de contar a história sobre uma pessoa, tornando-a a única história possível por meio de estereótipos (ADIECHIE, 2009). O problema dos estereótipos reside em sua incompletude, que faz com que uma história seja a única história (ADIECHIE, 2009). Uma história única rouba a dignidade das pessoas e torna o reconhecimento de sua igual dignidade humana difícil de ser percebida, uma vez que enfatiza suas diferenças (ADIECHIE, 2009).

De certa forma, o assédio moral cria uma história única para sua vítima ao repetir afirmações e/ou atitudes que minam seu reconhecimento perante o grupo de colegas de trabalho ou mesmo seu reconhecimento individual, tornando-a diferente dos demais. A identidade do trabalhador deve ser preservada como forma de garantir a concretização da identidade da Carta Constitucional, chamada de Constituição cidadã.

A construção de uma identidade constitucional requer uma abertura para o outro, implica a alteridade, assim como ocorre na formação da identidade individual (MENELICK, 1998, p. 152). Menelick de Carvalho Netto aponta, como demonstrou Hegel, que o risco dessa abertura para o outro é uma escravização à medida que para formar a sua identidade o indivíduo precisa autodeterminar-se sobre o outro em uma imposiçâo de força e dominação que acaba alienando ambas as partes (MENELICK, 1998, pp. 152153). "O reconhecimento alcançado pela vitória e a dominação do outro transforma-o em coisa dominada e, de imediato, o reconhecimento obtido perde qualquer valor, posto que equivalente ao reconhecimento que se busca por intermédio da posse das coisas, da demonstração externa de status" (MENELICK, 1998, p. 153).

Assim, a identidade empresarial que domina seu empregado não possui valor, uma vez que mina o reconhecimento da personalidade do trabalhador vítima do abuso. 


\section{Assédio moral e discriminação de gênero}

ChantalMouffe entende que a luta feminista e as demais lutas contemporâneas comunicam-se por meio da dialética em um projeto de democracia plural e radical, em uma cadeia de equivalências entre as demandas oriundas das mulheres, dos negros, dos trabalhadores, entre outros grupos (MOUFFE, 1992). Destarte, a articulação entre os diversos grupos e demandas é fator decisivo, permitindo que a posição de cada sujeito se construa nessa estrutura discursiva sem a fixação permanente, mas por meio de uma fixação parcial de identidade mediante a criação de pontos nodais (MOUFFE, 1992).

Há uma multiplicidade de relaçóes sociais nas quais a diferença de gênero se desdobra de diferentes modos e nas quais a luta contra a subordinação tem que ser implementada de formas específicas e diferenciadas (MOUFFE, 1992). Essa multiplicidade é observada no ambiente de trabalho, no qual se verifica a interseção entre demandas dos trabalhadores e demandas de mulheres, em uma dialética que combina demandas de classe e de gênero.

Nesse contexto de multiplicidade e interseção de demandas, pesquisas mostram que essa prática do assédio moral ocorre com maior frequência contra mulheres ${ }^{2}$ nos ambientes de trabalho (ALKIMIN, 2008, p. 117). No Brasil, os dados foram levantados pela médica do trabalho Margarida Barreto, indicando que $65 \%$ da vítimas de assédio moral são mulheres (BARRETO, 2006, pp. 29-32). Autores, como Aparecido Inácio Ferrari de Medeiros, afirmam que "quem mais sofre violência moral no trabalho são mulheres" (MEDEIROS, 2012, p. 63).

Marie-France Hirigoyen, com base em suas pesquisas realizadas na França sobre o assédio moral, constatou uma relação entre essa forma de violência moral e o gênero de suas vítimas:

Nosso estudo mostra uma clara diferença entre a distribuiçáo dos sexos: 70\% de mulheres contra $30 \%$ de homens. Estes números estão de acordo com os do trabalho do Dr. Chiaroni (73\% de mulheres), realizado com o auxílio de médicos do trabalho da regiāo PACA.

Diferem dos resultadosobtidos por BéatriceSilerea associação MotspourMauxau Travail, em Estrasburgo, que constatam 43,5\% de mulheres assediadas contra 56,5\% de homens, e por Heinz Leymann, na Suécia, segundo o qual 55\% de mulheres são afetadas contra $45 \%$ de homens, o que não constitui um afastamento significativo do ponto de vista estatístico. O estudo de S. Einarsen e A. Skogstad, realizado em 1996 na Noruega, apresenta igualmente números estatisticamente não-significativos: $55,6 \%$ de mulheres contra $43,9 \%$ de homens.

\footnotetext{
$2 \quad$ Uma das obras cinematográficas que mais chamou a atenção para a questão do assédio moral e sexual contra mulheres em profissões tradicionalmente masculinas foi a filmografia "Terra fria"(Original: North Country), Direção: Niki Caro. Roteiro: Michael Seitzman. Warner Bros. 2005. EUA.
} 
Mas é necessário atribuir tais percentagens ao contexto sociocultural. Os países escandinavos e a Alemanha manifestam uma real preocupação com a igualdade de oportunidades entre os dois sexos. Nos países latinos ainda reina uma atmosfera machista. Na Itália, na Espanha e na América Latina, muitos homens consideram que cada mulher que trabalha é culpada por um desempregado entre os homens.

As mulheres não somente são mais frequentemente vítimas, como também são assediadas de forma diferente dos homens: as conotaçôes machistas ou sexistas estão muitas vezes presentes. $\mathrm{O}$ assédio sexual não é mais do que uma evolução do assédio moral. Nos dois casos, trata-se de humilhar o outro e considerá-lo um objeto à disposição. Para humilhar, visa-se o íntimo. (HIRIGOYEN, 2012, pp. 99-100).

Adriane Reis de Araújo afirma que quando a vítima de assédio moral pertence a uma minoria torna-se difícil distinguir o assédio da discriminação (ARAÚJO, 2012, p. 87). Um bom exemplo para uma minoria são as mulheres, que ainda estão ganhando reconhecimento no mercado de trabalho, mas contam com um contexto sociocultural de discriminação por conta de estereótipos criados, esses são classificaçôes genéricas valoradas pela diferença no âmbito social sobre certos indivíduos (ARAÚJO, 2012, p. 87).

Marie-France Hirigoyen apresenta como um dos tipos de assédio moral o assédio de gênero e o define como a forma de "tratar uma mulher diferentemente por ser uma mulher, com comentários ou comportamentos sexistas" (HIRIGOYEN, 2002, p. 81).

Ao analisar a preponderância da prática do assédio moral contra mulheres, Candy Florencio Thome assinala a utilização de subterfúgios discriminatórios, como o argumento de que a vítima passa por "variações hormonais". Tais argumentos servem como estratégias defensivas para perpetuar a opressão na forma de assédio moral e desqualificar o sofrimento da vítima (THOME, 2008, p. 106).

A dimensão que o assédio moral atingiu contra as mulheres combinou o viés discriminatório e machista com um modelo de mercado desenraizado. Com relação ao mercado, ele será enraizado quando considerar normas não-econômicas para reger suas instituições, ou então será desenraizado quando for guiado pela oferta e procura sem se ater a controles extraeconômicos (FRASER, 2011, p. 620). Em regra, as civilizaçóes regulam o mercado e o tornam enraizado, para que haja a possibilidade de relaçóes sociais existirem, uma vez que o desenraizamento do mercado acaba provocando uma crise social (FRASER, 2011, p. 621).

Entretanto, Nancy Fraser alerta que essa visão acaba por romancear o mercado enraizado, como se este fosse incapaz de reproduzir formas de opressão, uma vez que o desenraizamento do mercado também pode trazer aspectos emancipatórios (FRASER, 2011, p. 622). Assim, a opressão pode vir de ambos os tipos de mercado (FRASER, 2011, p. 622). 
Para analisar as assimetrias que ambos os modelos de mercado ocultam, Nancy Fraser propõe a utilização dos ideais feministas por meio de uma categoria que denomina "emancipação" (FRASER, 2011, p. 622). Mesmo o mercado enraizado, fundamentado em mecanismos de proteção social, pode reforçar opressóes (FRASER, 2011, p. 623). Nancy Fraser propõe, assim, uma análise da dominação tanto oriunda da sociedade como do mercado sob a luz da emancipação (FRASER, 2011, p. 623).

A emancipação visa a uma análise mediada pela justiça a respeito tanto do mercado enraizado quanto do mercado desenraizado, buscando combater a dominação (FRASER, 2011, p. 623).

Para combater a reprodução de mecanismos opressores, Nancy Fraser utiliza-se da expressão "paridade de participação", conceito que divide em cinco pontos (FRASER, 2011, p. 623). São eles: a) a possibilidade de estar em condição de igualdade para interagir com os outros (o que não se pode determinar apenas de forma quantitativamente numérica); b) a paridade de participação deve considerar três dimensões: a distribuição econômica, o reconhecimento cultural e legal e a representação política; c) aplicação da paridade em todos os âmbitos da vida social e não apenas nas instituiçóes políticas; d) a paridade deve contemplar outras categorias discriminadas que não se limitam ao gênero; e) aplicação prática da paridade de forma a "avaliar a justiça em todos os arranjos sociais" (FRASER, 2011, p. 625).

Por acreditar que a retirada de um sistema de proteção que reforçava opressóes iria garantir maior igualdade de gênero, o movimento feminista acabou por negligenciar a ascensão do neoliberalismo e suas consequências (FRASER, 2011, pp. 628- 629). Em uma retrospectiva histórica, o movimento feminista de segunda geração teve duas orientaçôes, uma que combateu o estado social que reforçava proteçóes que oprimiam e geravam hierarquia social entre homens e mulheres, inserindo-se em uma lógica de mercantilização; e outra que sustentava uma proteçáo social reformulada de forma a promover uma maior igualdade entre homens e mulheres (FRASER, 2011, p. 630). Por fim, a orientação vitoriosa foi aquela em favor da mercantilização, por conceder uma remuneração a cada trabalhador(a) ao invés do antigo "salário família", mesmo que em um sistema de exploração, precarização do emprego, redução dos salários, aumento da jornada de trabalho (FRASER, 2011, p. 630). Assim, o neoliberalismo apropriou-se da crítica feminista ao "salário família" para implementar o "novo capitalismo flexível” (FRASER, 2011, p. 631).

Por fim, Nancy Fraser conclui que a emancipação das mulheres da hierarquia de gênero deve passar por um processo de conscientização dos desenvolvimentos que são ocupados por forças de mercantilização e criar novos laços com a proteção social para que se crie um movimento triplo que considere o combate à dominação, a solidariedade e a segurança social, bem como a liberdade negativa, em uma concepção mais abrangente de justiça social (FRASER, 2011, pp. 631-632). 


\section{A dificuldade em se comunicar experiências}

Hannah Arendt entende que a barbárie surge da banalização do mal que vem acompanhada da supressão da faculdade de pensar, uma vez que para fazer o bem é preciso pensar e desejá-lo (AREDNT, 2013, pp. 310-311). Para reproduzir o mal, mesmo sem ser seu idealizador, não é necessária uma inteligência ou mesmo pensar ou decidir, aqueles que funcionam como engrenagens para a reprodução do mal encontram-se com uma personalidade banalizada (AREDNT, 2013, pp. 310-311).

Essa apatia ou indiferença em relação à banalização do mal é explicada por Christophe Dejours como um processo formado por etapas que passa a "atenuar a consciência moral em face do sofrimento infligido a outrem e de criar um estado de tolerância ao mal" (DEJOURS, 2006, p. 139).

A apatia em relação à situação das vítimas de assédio moral por parte dos demais colegas de trabalho, em parte, é um reflexo da impossibilidade das vítimas manifestarem as situações de sofrimento enfrentadas frente aos colegas. Essa dificuldade de comunicação é fruto de um sistema neoliberal que pressiona, retrai e inibe os trabalhadores empregados.

Como coloca Walter Benjamin, "a experiência do corpo pela fome” na guerra torna as pessoas mais pobres em experiências comunicáveis (BENJAMIN, 1994, p. 115). Essa pobreza de experiência se transforma em barbárie (BENJAMIN, 1994, p. 116). Uma barbárie que as "impele a partir para a frente, a começar de novo, a contentar-se com pouco, a construir com pouco, sem olhar nem para a direita nem para a esquerda" (BENJAMIN, 1994, p. 116).

$\mathrm{Na}$ experiência do medo de perder o emprego, cada trabalhador sofre com as ameaças de demissão e as pressóes por melhor desempenho, sendo incapazes de comunicar esse sofrimento aos colegas por receio de transparecer uma personalidade fraca ou inapta a lidar com o sistema. De igual modo, os empregados ansiosos e pressionados não direcionam o olhar para o sofrimento dos colegas.

Percebe-se pela análise da conjuntura do sistema neoliberal que a mobilização coletiva dos trabalhadores está perdendo força e atividade, talvez por uma excessiva concentração no individual, na concorrência por uma vaga de emprego, pela necessidade de manter o posto de trabalho e o medo de perder o lugar que se ocupa para o "colega mais próximo". A ação coletiva encontra-se desmobilizada. E juntamente com ela encontra-se paralisada a capacidade de comunicar experiências.

Um dos reflexos da precarização das relações de trabalho mostra-se na ausência de comunicação de experiências. Christophe Dejours, ao falar sobre a França, aponta o seguinte efeito da precarização "que todos, dos operadores aos gerentes, se defendem da mesma maneira: negando o sofrimento alheio e calando o seu” (DEJOURS, 2006, p. 51). 
Christophe Dejours afirma que "o medo paralisa, pois quebra o 'moral' do coletivo", e esse fator também se observa até certo ponto nas guerras (DEJOURS, 2006, p. 58).

Walter Benjamin, ao fazer um paralelo com a guerra, descreve o fenômeno da incapacidade de comunicar experiências, que é recorrente na modernidade, da seguinte forma:

(...) as açôes da experiência estão em baixa, e tudo indica que continuarão caindo até que seu valor desapareça de todo. Basta olharmos um jornal para percebermos que seu nível está mais baixo que nunca, e que da noite para o dia não somente a imagem do mundo exterior mas também a do mundo ético sofreram transformaçôes que antes não julgaríamos possíveis. Com a guerra mundial tornou-se manifesto um processo que continua até hoje. No final da guerra, observou-se que os combatentes voltavam mudos do campo de batalha, não mais ricos, e sim mais pobres em experiência comunicável (BENJAMIN, 1994, p. 197).

A comunicação de experiências mostra-se de fundamental importância para as relaçóes de trabalho, inclusive entre colegas de trabalho.

Há um foco excessivo no indivíduo e esquece-se de uma experiência coletiva que tem uma abrangência mais generalizada. Christophe Dejours afirma que as pesquisas em psicopatologia do trabalho iniciadas nos anos 1970 incorriam "num pecado capital: o de privilegiar a subjetividade individual, de supostamente levar a práticas individualizantes e de tolher a ação coletiva" (DEJOURS, 2006, p. 38). O autor afirma que "tidas como antimaterialistas, tais preocupaçóes com a saúde mental tolheriam a mobilidade coletiva e a consciência de classe, favorecendo um 'egocentrismo pequeno-burguês' de natureza essencialmente reacionária" (DEJOURS, 2006, p. 38).

Assim, as organizaçóes sociais negligenciaram o sofrimento no trabalho e, em especial, as relaçóes entre subjetividade e trabalho (DEJOURS, 2006, p. 37). Destarte, negligenciando-se as subjetividades torna-se difícil criar uma identidade coletiva que possa ser compartilhada entre os trabalhadores, principalmente entre as vítimas de assédio moral e os demais colegas.

Segundo Christophe Dejours, essa negligência levou os sindicatos a desqualificarem o discurso sobre o sofrimento e a tolerarem o sofrimento subjetivo (DEJOURS, 2006, pp. 39-40).

Uma das teses do neoliberalismo passa a ser a retirada de identidade e sentido que antes o trabalho conferia aos obreiros (DEJOURS, 2006, p. 42). A grande questáo que se coloca a essa tese é que "o trabalho continua sendo o único mediador da realização do ego no campo social, e não se vê atualmente nenhum candidato capaz de substituí-lo” 
(DEJOURS, 2006, p. 43). O sofrimento que advém do trabalho decorre da degradação das relaçóes de trabalho e do fortalecimento dos sentimentos de individualismo, desconfiança e concorrência entre colegas (DEJOURS, 2006, p. 43).

\section{6. $\quad 0$ papel da justiça do trabalho na preservação da identidade das trabalhadoras}

$\mathrm{Na}$ visão habermasiana, em um Estado de Direito, para se efetivar o sistema democrático e seus direitos, "é preciso que se considerem as diferenças com uma sensibilidade sempre maior para o contexto" (HABERMAS, 2002, p. 235). No direito moderno, uma ordem jurídica para ser legítima precisa assegurar a mesma liberdade a todos os cidadãos, permitindo que cada um participe da construção do direito (HABERMAS, 2002, p. 242).

Os direitos fundamentais, originalmente pensados para garantir direitos aos cidadãos em sua relação com o Estado, ganharam eficácia também nas relações entre particulares, nas relaçóes privadas (PEREIRA, 2013, p. 138). Essa eficácia horizontal dos direitos fundamentais garante, assim, a proteção desses direitos contra ameaças oriundas de poderes privados (PEREIRA, 2013, p. 139). Assim, "o Estado está obrigado a, além de não os violar, dispensar-lhes proteção adequada quando violados por particulares" (PEREIRA, 2013, p. 139).

Por meio das açóes levadas à justiça do trabalho que colocam como objeto da discussão o assédio moral, os magistrados trabalhistas com uma sensibilidade para o contexto neoliberal bem como para as condições socioculturais de discriminação podem considerar as diferenças que o assédio busca suprimir de forma a reconhecer o sofrimento infligido às vítimas e punir tais práticas abusivas, mostrando a intolerância do ordenamento jurídico para com essa forma de gestão.

Luiz de Pinho Pedreira da Silva entende que a responsabilização pelo assédio moral encontra amparo no ordenamento jurídico inicialmente no artigo $5^{\circ}$, inciso $\mathrm{X}$, da Constituição da República, o qual declara a inviolabilidade da intimidade, vida privada, honra, imagem, assegurando o direito à indenização pelo dano material ou moral que viole tais direitos. No âmbito infraconstitucional, a reparação do assédio moral encontra respaldo no artigo 927 do Código Civil (SILVA, 2004, p. 102).

Em alguns municípios e estados brasileiros, já foram editadas leis tipificando o assédio moral no ambiente de trabalho com o fim de proteger servidores públicos contra o terror psicológico na Administração Pública (BARROS, 2009, pp. 192-193). Entretanto, igual medida não foi elaborada pelo legislador federal com relação aos empregados regidos pela CLT (BARROS, 2009, p. 193). 
Para amenizar a omissão do legislador nacional, Alice Monteiro de Barros sugere a utilização de Convenções Coletivas como instrumentos para conceituar o assédio moral, bem como estabelecer sanções que evitem essa forma de violência (BARROS, 2009, p. 193).

Quanto à valoração da indenização pelo dano gerado por assédio moral, há diversas teorias sobre sua forma de cálculo, bem como sobre seu caráter indenizatório, reparador, punitivo e sancionatório.

Alguns autores, como Gabba, Savigny, Baudry-Lacantinerie e Barde, entendem que o dano moral não pode ser reparado com uma indenizaçáo pecuniária, por ser um dano passageiro, não aferível monetariamente e insuscetível de avaliação econômica (SILVA, 2004, pp. 30-31). Outros autores, como Windscheid, Georges Ripert e Minozzi, sustentam a possibilidade de reparação patrimonial àquele que sofreu dano moral, conferindo à indenização tanto um caráter compensatório à vítima quanto uma natureza punitiva ao agressor (SILVA, 2004, p. 30).

$\mathrm{O}$ argumento de que a indenização é incapaz de restaurar a condição anterior ao dano moral é um argumento frágil, uma vez que mesmo na hipótese de dano material a reparação patrimonial nunca será exatamente capaz de restituir a situação anterior ao dano (SILVA, 2004, pp. 31-32).

Alguns civilistas, como Maria Helena Diniz, propóem que o órgão judicante ao fixar o arbitramento da indenização pelo dano moral deverá evitar um valor simbólico e a geração de um enriquecimento sem causa da vítima (DINIZ, 2001, pp. 266-267). A civilista defende a seguinte tese sobre a avaliação do dano moral:

(...) A indenização não poderá ter valor superior ao dano, nem deverá subordinarse à situação de penúria do lesado; nem poderá conceder a uma vítima rica uma indenização inferior ao prejuízo sofrido, alegando que sua fortuna permitiria suportar o excedente do menoscabo (DINIZ, 2001, pp. 266-267).

Por sua vez, Carlos Roberto Gonçalves considera que, além da condição econômica da vítima, o arbitramento da indenização por dano moral deve apreciar também a situação econômica do ofensor, em virtude do caráter punitivo da indenização (GONÇALVES, 2011, p. 404).

Como Luiz de Pinho Pedreira da Silva coloca, o argumento de que a indenização por dano moral pode gerar enriquecimento sem causa da vítima não se mostra válido em uma sociedade em que a ordem jurídica tutela bens morais e estabelece responsabilidade civil por danos morais (SILVA, 2004, p. 33).

O sistema atual tanto de gestão dos Estados como das empresas passa por um efeito de comercialização, na medida em que bens e atividades que antes não possuíam valoração monetária passam a adquirir um caráter comercial. O discurso do efeito de comercialização 
feito pelo mercado buscou sempre uma aparência de neutralidade diante de posiçóes morais e políticas. Entretanto, a valoração dos bens é uma questão de ordem moral e política, não meramente econômica; o triunfalismo de mercado levou à criação de uma sociedade de mercado, que é pautada na mercantilização de cada atividade humana de forma a moldar as relações sociais à imagem do mercado (SANDEL, 2012, p. 16). Michael Sandel propóe, então, a utilização do debate público como meio para a discussão sobre os limites morais do mercado (SANDEL, 2012, p. 18).

No caso do dano oriundo de assédio moral, a reparaçáo patrimonial mostra-se como uma forma de comunicar às organizações empresariais que as formas de gestão pela incitação e pelo sofrimento psicológico, as quais são empregadas com a crença de que promoverão maior produtividade, eficiência e lucros, na verdade terão como fim último uma perda desse suposto ganho financeiro que o assédio moral tenha contribuído para produzir. Se a única linguagem que as empresas entendem é a linguagem financeira, somente uma resposta que afete suas finanças e resultados será capaz de comovê-las ao ponto de repensar sua forma de gestão de pessoal.

Michael Sandel menciona o caso em que uma creche passou a cobrar um valor aos pais que se atrasassem para buscar seus filhos no fim dia, o resultado não foi uma redução nos atrasos, mas um aumento (SANDEL, 2012, p. 117).

A introdução de dinheiro em um contexto diverso do mercado é capaz de alterar o comportamento das pessoas e seu empenho moral e cívico, podendo a racionalidade do mercado corroer de tal forma as relações que o preço inicialmente estabelecido passe a ser insuficiente para se produzir o efeito pretendido inicialmente (SANDEL, 2012, p. 118). "Muitos economistas reconhecem atualmente que o mercado altera o caráter dos bens e das práticas sociais por ele governados" (SANDEL, 2012, p. 119).

Fred Hirsch, economista britânico, que atuou como assessor do Fundo Monetário Internacional, questionou se a atribuição de valor a um bem tem o mesmo efeito sendo estabelecido pelo mercado ou por outro fator, ao tratar do "efeito de comercializaçáo" (SANDEL, 2012, p. 119). Para o economista, o "efeito de comercialização" consistena oferta de produtos ou atividades de forma predominantemente comercial, ao invés de substituir a mercantilização por uma troca na forma de altruísmo ou amor, acreditando-se que o processo de comercialização não terá qualquer influência sobre o produto ou atividade (SANDEL, 2012, p. 119).

Michael Sandel cita outros economistas comportamentais que também criticam o efeito de comercialização, demonstrando que o dinheiro pode adquirir um caráter corrosivo enfraquecendo motivações ao invés de fomentá-las (SANDEL, 2012, p. 120).

Seguindo esse raciocínio proposto por Michael Sandel, é importante questionar os efeitos da mercantilização sobre as reparações dos danos gerados pelo assédio moral. Em 
razão da impossibilidade de se restaurar a situação existente antes da ocorrência do dano moral e em virtude da necessidade de se punir o agressor e compensar de algum modo a vítima, a reparação do assédio moral sofreu o efeito da comercialização. A Justiça do Trabalho deve, portanto, considerar que ao arbitrar o valor da indenização deve fixar um valor que não seja irrisório a ponto de levar a empresa ou o empregador a considerar a condenação como uma taxa a ser paga para que possa continuar a praticar assédio moral, mas que entenda o valor da indenização como uma punição por um conduta considerada repugnante pelo ordenamento jurídico.

A colocação do problema relativo ao valor da indenização por danos decorrentes do assédio moral deve considerar o efeito que se deseja alcançar com a condenação. Se o intuito é coibir as práticas de assédio moral, uma condenação baseada apenas na condição econômica da vítima com preocupaçóes em evitar seu enriquecimento ilícito poderá transformar-se, como no caso da taxa pelo atraso em buscar os filhos na creche, em um custo para se adotar o assédio como método de gestão.

Considerando que os danos psicológicos e até físicos em decorrência de efeitos psicossomáticos gerados pelo assédio moral jamais poderão ser compensados por meio de uma indenização monetária, a condenação pecuniária, além de atuar como forma de reconhecimento do sofrimento infligido à vítima, possui uma função punitiva primordial, como forma de demonstrar que essa forma de violência não é admitida pelo ordenamento jurídico. Destarte, o valor arbitrado deve ser suficiente para causar desconforto ao equilíbrio dos resultados financeiros da organização que tolera ou adota expressamente o assédio moral como método de gestão de seu pessoal. Caso contrário, o raciocínio a ser fomentado será o de que o custo de uma gestão que adota o assédio moral é apenas um pouco maior que aquele que não se admite essa prática, podendo as empresas considerarem viável arcar com o custo a depender dos resultados imediatos que pretendam alcançar.

Por todo o exposto, parece mais razoável fixar o valor da indenização com base nas condições econômicas do agressor ao invés de utilizar como base a capacidade econômicofinanceira da vítima.

Dessa forma, principalmente os magistrados do trabalho poderão por meio de suas decisôes concretizar a eficácia horizontal (SARLET, 2010, pp. 374-383) dos direitos fundamentais à personalidade, à integridade e à dignidade dos trabalhadores, senão com efeito reparador para o caso concreto, ao menos com um efeito pedagógico-preventivo para casos futuros. Por meio do efeito pedagógico da tutela jurisdicional implementa-se o que Dworkin define como o valor expressivo do direito como integridade: a possibilidade de cada indivíduo tratar as outras pessoas de forma apropriada como membros de uma mesma comunidade, mesmo quando possuem divergências (DWORKIN, 2007, pp. 230-231). 


\section{Conclusão}

O assédio moral é uma prática de violência tão antiga quanto o próprio trabalho. Entretanto, o seu reconhecimento como um problema ou uma disfunção a ser tratada somente ganhou a atenção dos estudiosos ao final do século XX. Psicólogos, médicos, sociólogos, juristas buscam definir e delimitar os contornos do assédio moral de forma a evitar que meros dissabores e conflitos pontuais sejam caracterizados como essa forma de violência sistematizada, o que poderia levar inclusive à banalização do uso do termo e uma desqualificação das reais situações de sofrimento.

$\mathrm{O}$ atual contexto neoliberal surge com um modo de gestáo pela incitação, o qual se vale de práticas de assédio moral para garantir a conformidade dos trabalhadores a um modelo de identidade empresarial. A pressão psicológica para se ajustar ao padrão posto pela organização visa, em última instância, a um aumento de eficiência e produtividade, eliminando toda dissidência que contrarie o padrão normalizador instituído.

Nesse sistema forjado no sofrimento psicológico para extrair das vítimas a maior rentabilidade possível, verifica-se que o índice de assédio moral é mais frequente entre mulheres. A discriminação de gênero não é característica exclusiva de um mercado desenraizado, ou sem regulamentação estatal, mas já foi utilizada também por mercados enraizados para reproduzir e manter formas de opressão de gênero. Entretanto, o grande problema consiste em ter o mercado desenraizado sido considerado a grande promessa de emancipação das mulheres, quando na verdade ele apenas reproduziu e reproduz também formas de desigualdade.

O assédio moral, em si, já é uma forma de desqualificar a igual consideração e respeito para com a sua vítima. Quanto se verifica que essa prática de violência é mais recorrente contra mulheres, observa-se que a opressão ganha contornos de dupla discriminação em uma tentativa de "normalizar" condutas e estereótipos de gênero.

Para um Estado Democrático de Direito, a igual consideração e respeito pela vida de todos os indivíduos representam o norte de atuação de todos os setores governamentais de forma a preservar identidades, coibir toda forma de discriminação, inclusive discriminações cumuladas. 


\section{REFERÊNCIAS}

ALKIMIN, Maria Aparecida. Violência na relaçáo de trabalho e a protectão à personalidade do trabalhador. Curitiba: Juruá Editora, 2008.

ARAÚJO, Adriane Reis de. O assédio moral organizacional. São Paulo: Editora LTr, 2012.

ARENDT, Hannah. Eichmmam em Jerusalém: uma relato sobre a banalidade do mal. Tradução: José Rubens Siqueira. São Paulo: Companhia das Letras, 2013.

BARRETO, Margarida. Assédio moral: violência psicológica que póe em risco sua vida. InL Coleçáo Saúde do Trabalhador, número 6, jan/2009 do SindQuim/SP.

SALVADOR, Luiz. Assédio moral. In: Revista Nacional de direito do trabalho, v. 8, n. 91, pp. 49-51, nov. 2005.

BARRETO, Margarida Maria Silveira. Violência, saúde e trabalho: uma jornada de humilhaçôes. São Paulo: EDUC, 2003.

BARROS, Alice Monteiro de. Proteçáo à intimidade do empregado. São Paulo: Editora LTr, 2a Ed., 2009.

BAUMAN, Zygmunt. Globalizaçáo: As conseqüências humanas. Tradução: Marcus Penchel. Rio de Janeiro: Jorge Zahar Editor, 1998.

BENJAMIN, Walter. Experiência e pobreza e O narrador. Considerações sobre a obra de Nikolai Leskov. In: BENJAMIN, Walter. Obras escolhidas, vol. 1 - magia e técnica, arte e política. Trad. Sérgio Paulo Rouanet. 7ª ed. Sáo Paulo: Brasiliense, 1994.

BOURDIEU, Pierre. Contrafogos. Rio de Janeiro: Jorge Zahar Editor,1998

CARVALHO NETTO, Menelick de. A hermenêutica constitucional e os desafios postos aos direitos fundamentais. In: Notícia do direito brasileiro. Nova série, no 6 . Brasília: Ed. UnB, $2^{\circ}$ semestre de 1998.

DEJOURS, Christophe. A banalizaçáo da injustiça social. Tradução: Luiz Alberto Monjardim. 7a edição, Rio de Janeiro: Ediotra FGV, 2006.

.A banalizaçáo da injustiça social. Tradução: Luiz Alberto Monjardim. 8a Edição, Rio de Janeiro: Fundação Getúlio Vargas Editora, 2007.

DINIZ, Maria Helena. O problema da liquidação do dano moral e dos critérios para a fixação do "quantum" indenizatório. In: Atualidades jurídicas 2. São Paulo: Saraiva, 2001.

DRAY, Guilherme Machado. O princípio da igualdade no Direito do Trabalho - Sua aplicabilidade no domínio específico da formação de contratos individuais de trabalho. Coimbra: Almedina, 1999.

DWORKIN, Ronald. O império do direito. Tradução: Jefferson Luiz Camargo; revisão técnica Gildo Sá Leitão Rios - São Paulo: Martins Fontes, 2003.

A virtude soberana - A teoria e a prática da igualdade. Tradução Jussara Simóes. São Paulo: Martins Fontes, 2005.

FRASER, Nancy. Mercantilização, proteção social e emancipação: as ambivalências do feminismo na crise do capitalismo. In: Revista Direito GV, São Paulo 7(2), jul-dez 2011. 
. Reconhecimento sem ética. São Paulo: Lua Nova, 70, 2007.

GONÇALVES, Carlos Roberto. Direito Civil Brasileiro, Volume 4. Responsabilidade Civil. São Paulo: Editora Saraiva, 6ª ed., 2011.

HABERMAS, Jürgen. O Futuro da Natureza Humana. A caminho de uma eugenia liberal? Trad.: Karina Jannini. São Paulo: Martins Fontes, 2010.

. A inclusáo do outro: estudos de teoria política. Trad.: George Sperber e Paulo AstorSoethe [UFPR]. São Paulo: Ediçôes Loyola, 2002.

HIRIGOYEN, Marie-France. Assédio Moral: a violência perversa no cotidiano. Tradução: Maria Helena Kühner. Rio de Janeiro: Bertrand Brasil, 10ª ed., 2008.

.Mal-estar no trabalho. Redefinindo o assédio moral. Rio de Janeiro: Editora Bertrand Brasil LTDA., 7ª ed., 2012.

Bertrand Brasil, 2002.

HONNETH, Axel. Luta por reconhecimento: a gramática moral dos conflitos sociais. Tradução: Luiz Repa. São Paulo: Editora 34, 2003.

LEYMANN, Heiz. The mobbingencyclopaedia. Disponível em: <http:/www.leymann.se/English/ frame.html> Acesso em: 1-11-2012.

MEDEIROS, Aparecido Inácio Ferrari de. Assédio moral, discriminaçáo, igualdade e oportunidades no trabalho. São Paulo: LTr Editora, 2012.

MOUFFE, Chantal. Feminismo, ciudadanía y política democrática radical. In: Feminists Theorize the Political. Ed. Judith Butler and Joan W. Scott, Routledge, 1992. Disponível em: <http://www.mujeresdelsur.org/sitio/images/descargas/chantal_ mouffe[1].pdf\%20ciudadania\%20y\%20feminismo.pdf> Acesso em: 26-1-2014.

NASCIMENTO, Sônia Mascaro. Panorama e perspectivas do assédio no ambiente de trabalho. In: Jornal Trabalhista Consulex, v. 29, n. 1425, maio 2012.

Assédio moral e bullying no ambiente de trabalho. In: Revista de Direito do Trabalho, v. 38, n. 145, p. 197, 2012, jan/mar 2012.

PEREIRA, Ricardo José Macêdo de. Os direitos fundamentais nas perspectivas civilista e trabalhista. In: TEPEDINO, Gustavo. MELLO FILHO, Luiz Phillipe Vieira. DELGADO, Gabriela Neves. (coordenadores) Diálogos entre o Direito do Trabalho e o Direito Civil. São Paulo: Editora Revista dos Tribunais, 2013.

ROSENFELD, Michel. A identidade do sujeito constitucional. Trad.: Menelick de Carvalho Netto. Belo Horizonte: Mandamentos Editora, 2003.

SANDEL, Michael J. O que o dinheiro não compra: os limites morais do mercado. Tradução: Clóvis Marques. Rio de Janeiro: Civilização Brasileira, 2012.

SARLET, Ingo Wolfgang. A eficácia dos direitos fundamentais. Porto Alegre: Livraria do Advogado, 2010.

SILVA, LeonardoMello e. Gestão pela incitação. In: Folha Sinapse, n. 37, 26 jul. 2005.

SILVA, Luiz de Pinho Pedreira da. A reparaçáo do dano moral no direito do trabalho. São Paulo: Editora LTr, 2004. 
SOARES, Andrea Antico. O assédio moral no trabalho sob a perspectiva dos direitos humanos e fundamentais. In: RevistaSíntese: trabalhista e previdenciária, v. 23, n. 276, pp. 42-52, fev.2012.

SOUTO MAIOR, Jorge Luiz. O direito do trabalho como instrumento de justiça social. São Paulo, LTr: 2000.

VIEIRA, Fernando Borges. A indústria do assédio moral ea banalização do direito. In: Jornal Trabalhista Consulex, v. 29, n. 1412, p. 13, fev. 2012.

\section{Ricardo Macedo de Britto Pereira}

Universidade de Brasília

Pesquisador e líder do Grupo de Pesquisa Trabalho, Constituição e Cidadania, da Faculdade de Direito da Universidade de Brasília (UnB/CNPq).

E-mail: rjmacedo@superig.com.br

Currículo lattes: http://lattes.cnpq.br/5151649835128510

\section{Lara Parreira de Faria Borges}

Universidade de Brasília

E-mail: lara.parreirafb@gmail.com

Currículo lattes: http://lattes.cnpq.br/4894157587501457 